\title{
Genome-Wide Association Study Dissects Resistance Loci against Bacterial Blight in a Diverse Rice Panel from the 3000 Rice Genomes Project
}

\author{
Jialing Lu' ${ }^{1,2}$, Chunchao Wang ${ }^{1}$, Dan Zeng ${ }^{1}$, Jianmin $\mathrm{Li}^{1}$, Xiaorong Shi ${ }^{1,3}$, Yingyao Shi ${ }^{3}$ and Yongli Zhou ${ }^{{ }^{*}}$ (D)
}

\begin{abstract}
Background: Bacterial blight (BB), caused by Xanthomonas oryzae pv. oryzae (Xoo) is one of the most devastating bacterial diseases of rice in temperate and tropical regions. Breeding and deployment of resistant cultivars carrying major resistance $(R)$ genes has been the most effective approach for BB management. However, because of specific interaction of each $R$ gene with the product of the corresponding pathogen avirulence or effector gene, new pathogen strains that can overcome the deployed resistance often emerge rapidly. To deal with ever-evolving Xoo, it is necessary to identify novel $R$ genes and resistance quantitative trait loci (QTL).

Results: BB resistance of a diverse panel of 340 accessions from the 3000 Rice Genomes Project (3 K RGP) was evaluated by artificial inoculation with four representative Xoo strains, namely Z173 (C4), GD1358 (C5), V from China and PXO339 (P9a) from Philippines. Using the 3 K RG 4.8mio filtered SNP Dataset, a total of 11 QTL associated with $\mathrm{BB}$ resistance on chromosomes 4, 5, 11 and 12 were identified through a genome-wide association study (GWAS). Among them, eight resistance loci, which were narrowed down to relatively small genomic intervals, coincided with previously reported QTL or $R$ genes, e.g. $x a 5, x a 25, x a 44(t)$. The other three QTL were putative novel loci associated with $\mathrm{BB}$ resistance. Linear regression analysis showed a dependence of BB lesion length on the number of favorable alleles, suggesting that pyramiding QTL using marker-assisted selection would be an effective approach for improving resistance. In addition, the Hap2 allele of LOC_Os11946250 underlying qC5-11.1 was validated as positively regulating resistance against strain $\mathrm{C} 5$.
\end{abstract}

Conclusions: Our findings provide valuable information for the genetic improvement of BB resistance and application of germplasm resources in rice breeding programs.

Keywords: Rice, Germplasm, GWAS, Bacterial blight

\section{Background}

Rice (Oryza sativa L.), an important cereal crop that supports more than $50 \%$ of the world population, suffers many biotic and abiotic stresses that lead to serious damage to crop yield and food safety (Oerke 2006). Rice

\footnotetext{
*Correspondence: zhouyongli@caas.cn

'National Key Facility for Crop Gene Resources and Genetic Improvement, Institute of Crop Sciences, Chinese Academy of Agricultural Sciences, Beijing 100081, China

Full list of author information is available at the end of the article
}

bacterial blight (BB), caused by Xanthomonas oryzae pv. oryzae $(X o o)$, is one of the most destructive bacterial diseases worldwide, in both tropical and temperate regions (Mew 1978). As it is a vascular disease, chemical measures for controlling BB are less effective than for some other diseases (Niño-Liu et al. 2006). Breeding resistant cultivars is considered the most effective and ecofriendly strategy for managing this disease (McDonald and Linde 2002). Because of the adaptation between rice and $\mathrm{Xoo}$, it is necessary to identify major resistance $(R)$ 
genes and quantitative trait loci (QTL) that will support the development of new resistant varieties.

To date, 45 major resistance genes (denoted $X a 1-x a$ $45(t))$ that confer resistance to BB have been identified, and are distributed on all chromosomes except chromosomes 9 and 10 (Chukwu et al. 2019; Kim 2018; Kim and Reinke 2019; Neelam et al. 2020). Most BB resistance genes were detected through bi-parental population $\left(\mathrm{F}_{2}\right.$ or recombinant inbred line populations) studies except for $\mathrm{Xa43}(\mathrm{t})$, which was discovered in a multi-parent advanced generation inter-cross (MAGIC) population through genome-wide association study (GWAS) (Kim and Reinke 2019). Among the 45 major resistance genes, 11 genes (Xa1, Xa3/Xa26, Xa4, xa5, Xa10, xa13, Xa21, $X a 23, x a 25, X a 27$ and $x a 41(t))$ have been cloned and characterized (https://shigen.nig.ac.jp/rice/oryzabase/). Because of either their lower level of resistance or their narrow spectrum of resistance, only a few genes (such as $\mathrm{Xa4}, \mathrm{Xa21}, \mathrm{Xa} 23$ and Xa39) with broad-spectrum resistance have been widely deployed in breeding programs so far (Hu et al. 2017; Song et al. 1997; Wang et al. 2015; Zhang et al. 2015). Some resistance genes linked to undesirable agricultural traits cannot be directly applied in breeding, such as $x a 13$, which improves $\mathrm{BB}$ resistance but reduces pollen fertility and seed setting rate ( $\mathrm{Li}$ et al. 2020). Furthermore, with the emergence of new and more virulent Xoo strains, single resistance genes can be overcome in a short period (McDonald and Linde 2002). Hence, in order to manage this disease effectively, it is necessary to identify QTL associated with BB resistance using new strategies, and to pyramid multiple genes/ QTL or introduce genes conferring broad-spectrum resistance and so breed durable resistance cultivars through advanced breeding programs.

Much progress has been made in identifying genes associated with desirable traits in rice using recent advanced sequencing technology (Peng et al. 2020; Wang et al. 2019; Wang et al. 2018). A large body of genotype data has been obtained in rice, including single nucleotide polymorphisms (SNPs), insertions and deletions (INDEL), structure variation (SV), and transposons, and these high-density markers have facilitated gene identification (Carpentier et al. 2019; Fuentes et al. 2019; Wang et al. 2020). In the past 5 years, GWAS based on SNP genotypes has become a popular and powerful tool to mine genes/QTL for complex agricultural traits including resistance to biotic and abiotic stress in rice, wheat and maize (Huang et al. 2015; Li et al. 2019b; Liu et al. 2017; Wang et al. 2016; Yano et al. 2019; Zhang et al. 2017b; Zhao et al. 2018). Different from traditional genetic mapping using bi-parental populations, GWAS can result in a relatively high mapping resolution and can detect more alleles at one locus by exploiting larger numbers of historical recombination events in varieties with more genetic diversity (Takeda and Matsuoka 2008). Notably, several genes related to rice diseases have been detected by GWAS (Kang et al. 2016; Zhang et al. 2017a; Zhang et al. 2019). For example, 13 resistance loci against rice black-streaked dwarf virus disease were detected in a rice diversity panel of 420 accessions using a $44 \mathrm{~K}$ SNP assay (Feng et al. 2019). Using the same set of germplasm and genotyping data, blast resistance was also evaluated by genome-wide association mapping and a new Pik allele was identified ( $\mathrm{Li}$ et al. 2019a).

There have been several studies aimed at detecting rice BB resistance through GWAS. A MAGIC population of 1328 lines was evaluated for BB resistance, and QTL on chromosome 11 and 5 flanking known genes $\mathrm{Xa} 4$ and xa5 were discovered (Bandillo et al. 2013). Using a MAGIC population derived from eight parents, four QTL for Chinese weak virulent strain C2 and four QTL for strong virulent strain $\mathrm{V}$ were identified; two of them conferred resistance to both $\mathrm{C} 2$ and $\mathrm{V}$ (Chen et al. 2016). Two major loci, $q B L B 11.1$ and $q B L B 5.1$, were identified for BB resistance in a rice MAGIC-plus population (Descalsota et al. 2018). The gene $X a 43(t)$ was identified from a japonica MAGIC population of 120 lines and confirmed using a bi-parental population (Kim and Reinke 2019). A rice panel of 285 cultivars was inoculated with nine representative Xoo strains from Philippines to identify loci associated with BB resistance: strong associations were found for novel SNPs linked with known genes Xa4, xa5, Xa7, xa13, Xa14, Xa21, xa25 and significant SNPs on chromosomes 6, 9, 11 and 12 were considered as novel sources of resistance (DillaErmita et al. 2017). In addition, 12 genomic regions significantly associated with $\mathrm{BB}$ resistance against Philippines Xoo strains PXO61 (P1), PXO99 (P6), PXO339 (P9a) were identified in 172 indica rice accessions through GWAS, but no significant SNP for Chinese Xoo strains GD1358 (C5) or V was detected (Zhang et al. 2017a). Using 267 rice accessions, 15 QTL were identified for resistance against $X o o$ race $\mathrm{C} 1$ (Li et al. 2018). Eleven broad-spectrum resistance QTL were detected as effective against $\mathrm{BB}$ and bacterial leaf streak (Bossa-Castro et al. 2018). Also, by analyzing sequences of 1479 rice accessions, some selected regions were identified as overlapping with related agronomic trait genes RfI and SD1 and with BB resistance genes Xa4 and Xa26 (Xie et al. 2015).

$\mathrm{BB}$ is an important disease of rice and often occurs in Central and South China, resulting in heavy yield losses (Zhang 2009). Hence, it is imperative to exploit genetic resources and discover genes conferring resistance to representative Xoo strains from China. In this study, a diverse rice panel of 340 accessions from the 3000 Rice Genomes Project (3 K RGP) (Wang et al. 2018) was 
inoculated with three Xoo representative strains of epidemic pathotypes from China and a representative strain from Philippines to evaluate their resistance against BB. Based on the 3 K RG 4.8mio filtered SNP Dataset (Mansueto et al. 2017), QTL associated with BB resistance were identified by GWAS. The cultivars carrying high resistance to multiple strains and 11 QTL for $\mathrm{BB}$ resistance were identified. An uncharacterized gene $L O C_{-}$ Os11g46250 was shown to be associated with resistance to strain C5. Our findings will facilitate the introduction of enhanced $\mathrm{BB}$ resistance in rice breeding programs.

\section{Methods}

\section{Plant Materials and Evaluation of BB Resistance with} Artificial Inoculation

A panel of 340 rice accessions was randomly selected from the sequenced accessions of the $3 \mathrm{~K}$ RGP, comprising $226 \mathrm{XI}$ (Xian/Indica), 65 GJ (Geng/Japonica), $30 \mathrm{cA}$ (circum-Aus), $8 \mathrm{cB}$ (circum-Basmati) and 11 Admix (accessions between XI and GJ groups) (Wang et al. 2018). Seeds were soaked in sterilizing agent before sowing to prevent seed borne-disease and germinated in seedling trays with nutritional soil in the nursery house $\left(25^{\circ} \mathrm{C}\right.$, light $12 \mathrm{~h} /$ dark $12 \mathrm{~h}$ ). The 30 -day-old seedlings were transplanted to the experimental farm at the Institute of Crop Sciences, Chinese Academy of Agricultural Sciences, Beijing, China. All the accessions were grown by two rows in a randomized complete block design with three replications. Each row contained eight plants spaced $20 \mathrm{~cm}$ apart. The fertilizer for the experimental farm was applied according to the previous report (Zhai et al. 2020). During the plants growing period, the average temperature was about $28{ }^{\circ} \mathrm{C}$ and the daylength was $12-14 \mathrm{~h}$ in summer in Beijing. Agronomic management was performed according to local practices without bactericide.

The representative Xoo strains Z173 (C4), GD1358 (C5), and V from China were used to evaluate the resistance of the 340 rice accessions. The representative strain of Philippine race 9 PXO339 (P9a), which was used in different panels for GWAS in previous studies (DillaErmita et al. 2017; Zhang et al. 2017a), was also used to identify novel resistance loci in this study. The four strains were cultured on potato peptone sucrose medium at $28^{\circ} \mathrm{C}$ for $48 \mathrm{~h}$ (Zhou and Zhang 1999), and each inoculum was prepared by suspending the bacterial mass in sterile water at a concentration of $10^{8}$ cells $\mathrm{ml}^{-1}$.

Four plants of each accession were inoculated with each strain in each replication using a leaf-clipping method (Kauffman et al. 1973) at the tillering stage (about 60-day-old seedlings). The lesion length (LL) was measured on the five uppermost leaves of each plant at 3 weeks post-inoculation when lesions were obvious and stable. The LL for each accession was calculated from four individual plants for each replication. The mean values of three replications for 340 rice accessions against each strain were used to generate a phenotype data matrix. Based on LL, the accessions were rated as resistant $(\mathrm{LL}<5 \mathrm{~cm})$, moderately resistant $(5 \mathrm{~cm} \leq \mathrm{LL}<$ $10 \mathrm{~cm})$, moderately susceptible $(10 \mathrm{~cm} \leq \mathrm{LL}<15 \mathrm{~cm})$ and susceptible ( $\mathrm{LL} \geq 15 \mathrm{~cm}$ ) (Zhang et al. 2017a).

\section{Genotype and Population Structure of Rice Accessions}

The genotypes of 340 accessions were derived from the $3 \mathrm{~K}$ RG 4.8mio filtered SNP Dataset (Mansueto et al. 2017; http://snp-seek.irri.org/download.zul). Using the linkage disequilibrium (LD) pruning tool of PLINK 1.9 (Purcell et al. 2007), we obtained independent SNPs with genotype missing rate $\leq 5 \%$ and minor allele frequency $\geq$ $1 \%$ according to the settings "indep-pairwise 50100.5 ". These SNPs were used to construct a phylogenetic tree with PHYLIP v3.696 and iTOL v5 (Letunic and Bork 2006; Shimada and Nishida 2017). The genetic structure of all accessions was predicted with the ADMIXTURE program (Alexander et al. 2009). K values were set from 2 to 9 and the minimum coefficient of variation $(\mathrm{CV})$ error value appeared at $\mathrm{K}=3$. Smart PCA in the software EIGENSOFT was used to perform principal component analysis (PCA) for calculating the subpopulation number (Galinsky et al. 2016).

\section{Genome-Wide Association Analysis of BB Resistance}

A total of 4,130,496 SNPs from 340 rice accessions with the criteria of genotype missing rate $\leq 5 \%$, minor allele frequency $\geq 1 \%$, were obtained for association analysis. The Balding-Nichols method was used to develop a kinship matrix (Balding and Nichols 1995). The software Efficient Mixed-Model Association eXpedited (EMMAX) was used to perform GWAS through SNP genotypes and phenotype matrixes under PCA and kinship as covariations (Kang et al. 2010). GEC software was used to calculate the effective number of independent markers and significant $P$-value threshold ( $\mathrm{Li}$ et al. 2012). Manhattan and quantile-quantile plots were created with the R package CMplot (https://github.com/YinLiLin/RCMplot).

\section{Identification of QTL Associated with BB Resistance and Prediction of Candidate Genes}

According to the previous studies, a region containing more than two SNPs above the significant $P$-value threshold in one estimated LD block were clustered as one QTL associated with BB resistance ( $\mathrm{Li}$ et al. 2018; Guo et al. 2020) and the SNP with minimum $P$-value within each QTL was considered as the lead SNP (Zhang et al. 2019). Those chromosomes containing more than two QTL were referred to as hotspot chromosomes. The 
continuous region closely linked to the lead SNP $\left(\mathrm{r}^{2} \geq\right.$ 0.6) was considered as the local LD interval (Yano et al. 2016), and the heatmap of LD block was drawn with the R package LDheatmap (Purcell et al. 2007; Shin et al. 2006). SNP effects within QTL were annotated from Effect of 29mio biallelic SNPs on Rice Genome Annotation Project rel 7 gene models (https://snp-seek.irri.org).

Haplotype analysis for candidate genes within each QTL was performed based on the significant SNPs and these genes can be classified into several major haplotypes (at least containing 10 accessions). Then combining with phenotype data, variations in LL explained by different haplotypes were analyzed by ANOVA. The genes that displayed significant LL differences among haplotypes were chosen for further research.

\section{Analysis of the Effect of Favorable Alleles on BB Resistance}

Each SNP has two alleles differing by a single nucleotide variation. Alleles with negative effects leading to shorter LL (associated with a more resistant phenotype) are referred to as favorable alleles (Bossa-Castro et al. 2018; Liu et al. 2017). The lead SNPs in the resistance loci were used to count the number of favorable alleles for all accessions and their allelic effects were determined between favorable alleles and LL using the ggplot2 package (Wickham 2009).

\section{Function Validation of Candidate Gene LOC Os11g46250} The genomic DNA fragment of LOC_Os11g46250, comprising about $2 \mathrm{~kb}$ of promoter region, the full genomic sequence and $1 \mathrm{~kb}$ downstream sequence, was amplified from accession Yunlu 102 (3K_ID CX355) with the resistant allele (Hap2) of LOC_Os11g46250. The amplification reaction was performed under the following condition: $95^{\circ} \mathrm{C} 3 \mathrm{~min} ; 95^{\circ} \mathrm{C} 15 \mathrm{~s}, 60^{\circ} \mathrm{C} 15 \mathrm{~s}, 72^{\circ} \mathrm{C} 6$ min, 35 cycles; $72^{\circ} \mathrm{C} 5 \mathrm{~min}$. The fragment was cloned into plant binary vector pCAMBIA1300 (Biovector NTCC Inc., Beijing, China) digested by BamH I and Hind III to generate a complementary construct with the native promoter. Then the complementary construct was introduced into Agrobacterium tumefaciens strain EHA105 and subsequently transferred to rice variety Nipponbare (Nishimura et al. 2006). Transgenic lines were identified using the hygromycin resistance gene and a set of primers for the vector and gene fragment. Expression level of LOC_Os11g46250 in the transgenic lines and wild-type were tested in $20-\mu \mathrm{L}$ reactions using the TransScript Two-Step RT-PCR SuperMix (Trans, Beijing, China) following the manufacturer's protocol via an ABI Prism 7900 Sequence Detection System (Applied Biosystems, Shanghai, China). The rice ubiquitin gene (LOC_Os03g13170) was used as the internal control. All primers used in this study are listed in Table S1.
To evaluate their resistance to strain $C 5$, all the $T_{2}$ lines and wild-type Nipponbare were planted in the transgenic experiment base (the same growing condition with the experiment farm) at the Institute of Crop Sciences, Chinese Academy of Agricultural Sciences, Beijing, China and inoculated with C5.

\section{Results \\ Population Structure of Rice Accessions}

Based on 527,165 independent SNPs with genotype missing rate $\leq 5 \%$ and minor allele frequency $\geq 1 \%$, a phylogenetic tree was developed using the neighborjoining method, dividing 340 accessions into four distinct major clusters (except for a small subgroup Admix), namely XI, GJ, cA and cB subgroups (Fig. 1a). Through principal component analysis, a similar result was observed, in which most of the genetic variation could be explained by the first two principal factors, largely consistent with the $3 \mathrm{~K}$ accessions classification (Fig. 1b). Based on the minimum CV error value $(K=3)$, all the accessions were grouped into three major subgroups (Fig. 1c). These results suggested that the accessions used as a covariate within the GWAS model displayed a clear population structure.

\section{Evaluation of Resistance to Four Xoo Strains}

The distribution of lesion length (LL) in 340 accessions inoculated with four Xoo strains (C4, C5, V and P9a) showed large phenotypic variation (Fig. S1). Among the inoculated cultivars, eight accessions were highly resistant to all four strains with $\mathrm{LL}<5 \mathrm{~cm}$, and 54 were highly susceptible to all four strains with $L L \geq 15 \mathrm{~cm}$ (highlighted in green and yellow, respectively, in Table S2). Another cultivar IRBB 7 (3K_ID CX134) from Philippines conferred high resistance to three Chinese strains (LL $0.5-1.5 \mathrm{~cm}$ ), but exhibited a loss of resistance to Philippines strain P9a (LL $15.8 \mathrm{~cm}$ ). Of the cultivars that were highly susceptible to all strains, Chinese cultivars accounted for about 50\%, suggesting that it is urgent to identify novel genes to deploy in rice breeding for China.

Based on the LL of all accessions, the four Xoo strains were divided into two obvious groups, namely Philippines strain group (P9a) and Chinese strain group (C4, C5 and V) (Fig. 2a). At the same time, 340 rice accessions formed three major clusters, based on the reaction to the four strains. Cultivars within one cluster exhibited similar resistance against different strains (Fig. 2a). According to classification by LL, a large number of accessions were moderately susceptible or susceptible, with $49.71 \%, 80.59 \%, 92.06 \%$ and $49.12 \%$ for strains C4, C5, V and P9a, respectively (Fig. 2b). For all strains, the average LL of subgroup GJ was significantly shorter than 
A

C
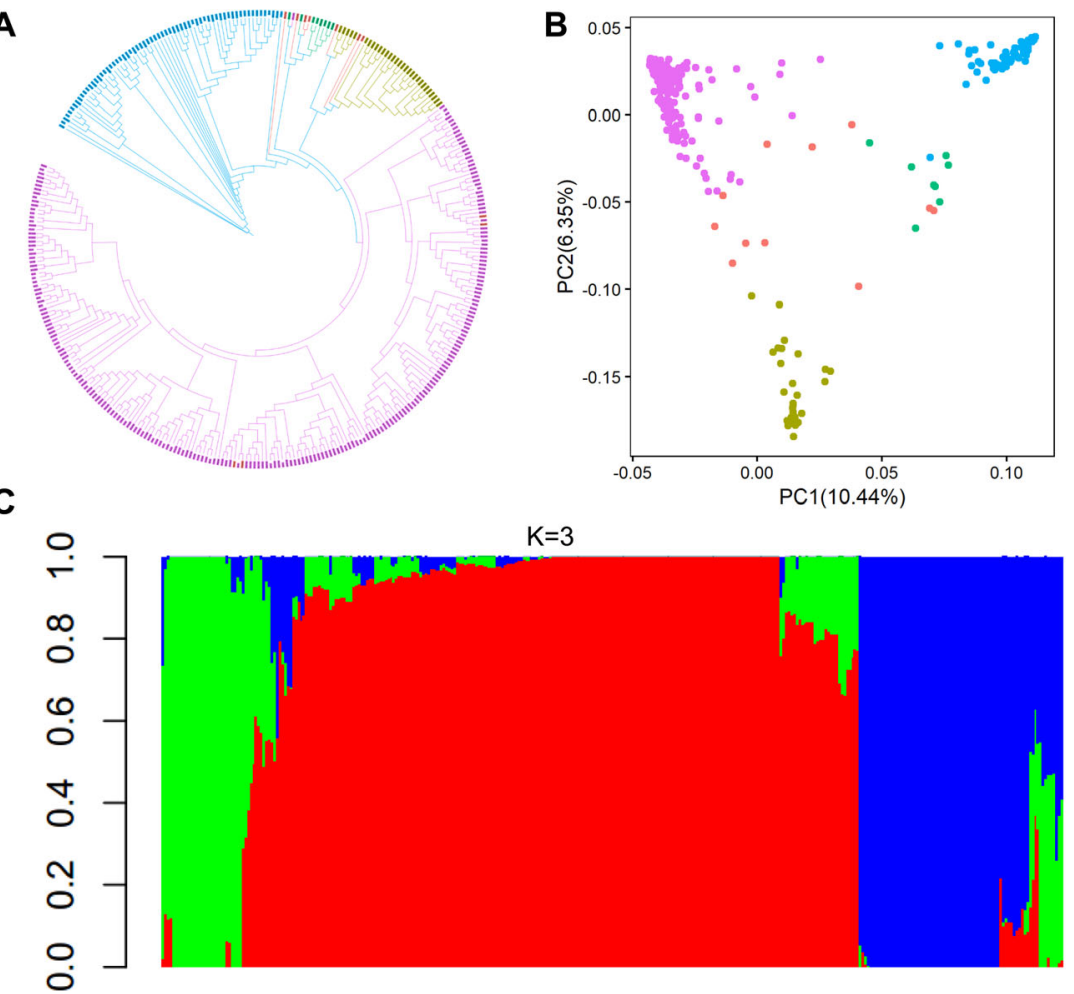

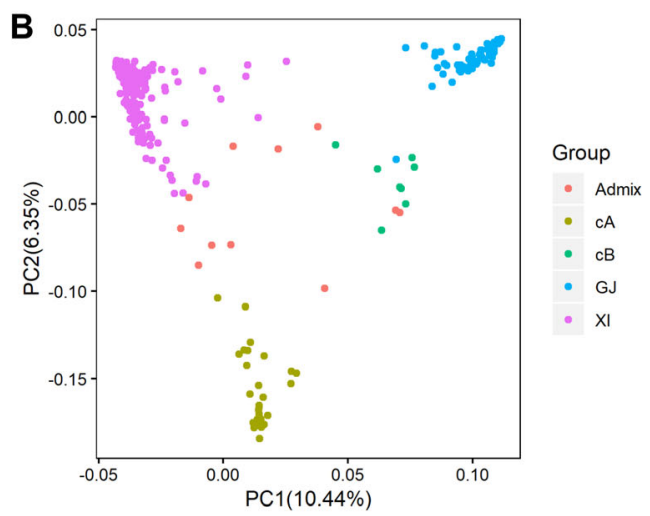

Admix

Fig. 1 Population structure analysis of the diverse rice panel used in this study. a Phylogenetic tree of 340 rice accessions. b Principal component analysis for the first two components of 340 accessions. c Distribution of the estimated subpopulations component for individual accessions

that of subgroup XI $(P<0.001)$. Also, for both strains $\mathrm{V}$ and $\mathrm{P9a}$, the average LL of subgroup XI was significantly longer than that of subgroup cA $(P<0.05)$ (Fig. 2c). These results indicated that rice cultivars in subgroup XI were more susceptible than those in other subgroups.

\section{Identification of Resistance Loci against BB}

To dissect genome-wide associated resistance loci for three Chinese Xoo strains and one Philippines Xoo strain, we performed GWAS with a mixed linear model of the EMMAX program using 4,130,496 high quality SNPs and LL as genotype and phenotype data, respectively. Based on the effective number of independent markers, the threshold of significant $P$-value was estimated to be $6.31 \mathrm{E}-8$ by the Bonferroni correction method. In total, we identified 11 QTL within 1576 unique SNPs associated with $\mathrm{BB}$ resistance to four strains (Fig. 3; Table 1). Among them, one, five, two and three QTL were detected to be associated with resistance to strains C4, C5, V and P9a, respectively. In detail, these significant SNPs were distributed on chromosomes 4, 5, 11 and 12, including four significant SNPs for C4, 80 for C5, 370 for $\mathrm{V}$ and 1173 for P9a (Table S3). Interestingly, 51 significant SNPs were identified as associated with resistance to both $\mathrm{C} 5$ and $\mathrm{V}$, suggesting that resistance to distinct strains might be controlled by the same resistance loci.

For strain $\mathrm{C} 4$, we identified only one resistance locus, qC4-11, defined by four significant SNPs within the region 27,382,744-27,579,384 bp on chromosome 11. These four SNPs were located in OsGPAT3 (LOC_Os11g45400), which played an indispensable role in pollen and anther development, including anther wall programmed cell death (Men et al. 2017; Sun et al. 2018).

For strain C5, five QTL were identified as associated with BB resistance, located on chromosomes 4, 5, 11 (two QTL), and 12. Notably, a cluster of significant SNPs on chromosome 11 were located in the genomic region 27,985,691$28,479,727 \mathrm{bp}$. Based on linkage disequilibrium analysis, the continuous region of chromosome 11 were divided into two QTL, namely $q C 5-11.1$ and $q C 5-11.2$.

For strain $\mathrm{V}$, there was a steep peak of resistancerelated SNPs on chromosome 5, defined by two QTL. The $q V-5.1$ region harbored 272 significant SNPs, overlapping with a broadly effective recessive resistance gene $x a 5$. Notably, no QTL or gene for BB resistance was previously reported in the other QTL, $q V-5.2$ (444,857-476, $382 \mathrm{bp}$ ), spanning about $31 \mathrm{~kb}$ on chromosome 5 . This region contained 98 significant SNPs and might include potential novel BB genes. 

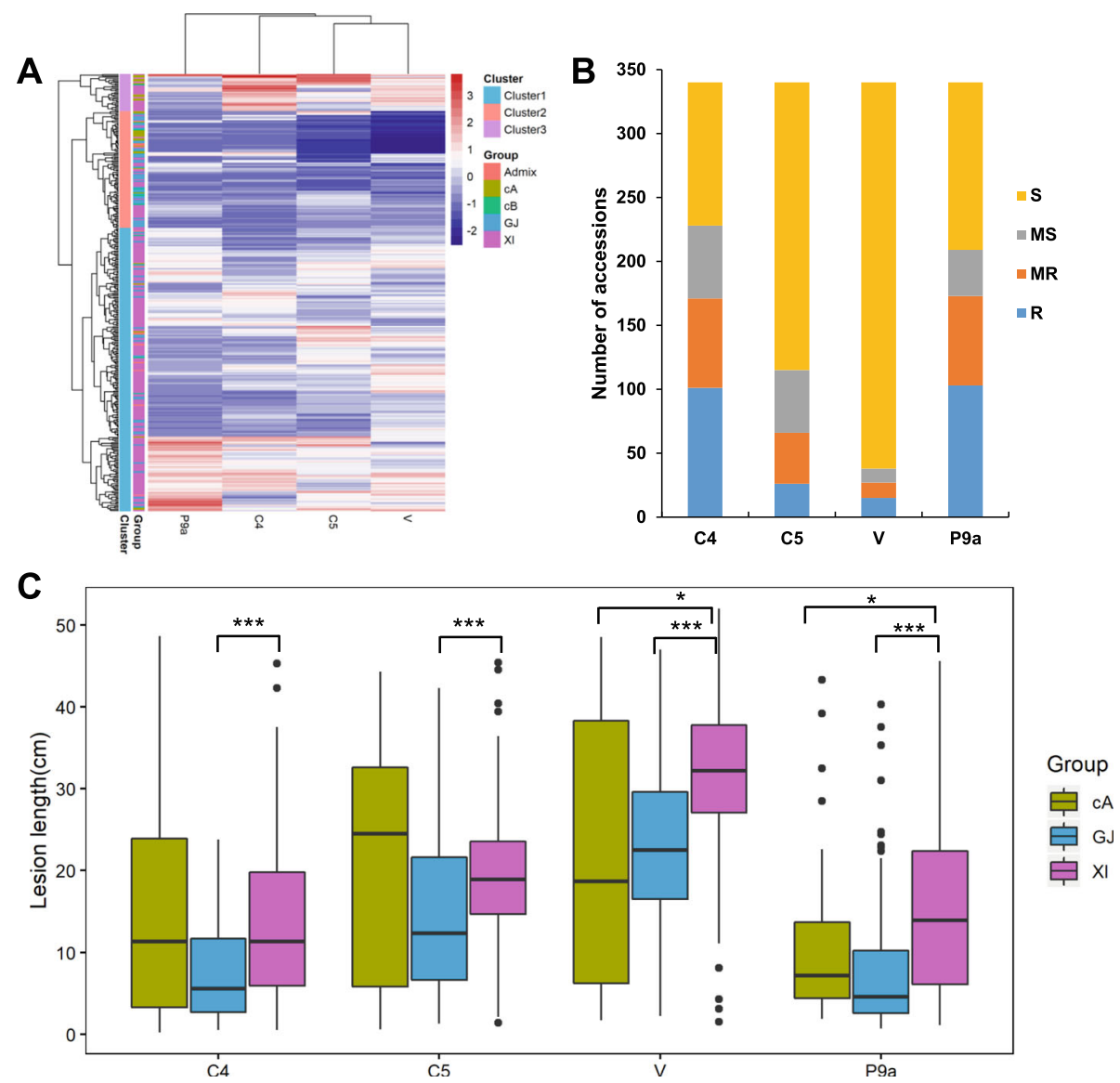

Fig. 2 Bacterial blight resistance evaluation of 340 rice accessions inoculated with representative Xoo strains from China and Philippines. a Hierarchical cluster of accessions and strains based on lesion length (LL). $\mathbf{b}$ Number of accessions showing different reactions to four $X_{00}$ strains. $R(L L<5 \mathrm{~cm}), M R$ $(5 \mathrm{~cm} \leq \mathrm{LL}<10 \mathrm{~cm})$, MS $(10 \mathrm{~cm} \leq \mathrm{LL}<15 \mathrm{~cm}), \mathrm{S}(\mathrm{LL} \geq 15 \mathrm{~cm})$. c Boxplots for $\mathrm{LL}$ of four Xoo strains in three major subgroups. Box edges represent the 0.25 and 0.75 quantiles with median values indicated by bold lines. ${ }^{*}$ and ${ }^{* * *}$ denote significant differences in mean $L L$ among subpopulations at $P<0.05,0.001$, respectively

For strain P9a, we identified 1173 significant SNPs associated with BB resistance on chromosome 12. Based on linkage disequilibrium analysis, this region was divided into three QTL ( $q P 9 a-12.1-q P 9 a-12.3)$. Among them, $q P 9 a-12.2$ was located close to the reported racespecific resistance gene $x a 25$.

\section{Hotspot Chromosomes Associated with BB Resistance}

The above GWAS results indicated chromosomes 5, 11, and 12 as hotspots for BB resistance. Strikingly, chromosome 11 contained multiple resistance loci for different Xoo strains, including one for $\mathrm{C} 4$ and two for $\mathrm{C} 5$, i.e. $q C 4-11, q C 5-11.1$ and $q C 5-11.2$ (Table 1). The sole QTL related to $\mathrm{C} 4$ resistance, $q C 4-11$, contained about $196 \mathrm{~kb}$ interval, in which the significant SNPs were located in the region of OsGPAT3. Of the QTL for C5 resistance, $q C 5-11.1$ spanned an approximately $27 \mathrm{~kb}$ interval (27,985,691-28,013,096 bp), while qC5-11.2 spanned about $49 \mathrm{~kb}$. Of particular note, a recessive gene $x a 44(t)$, conferring resistance to Xoo isolate HB1009
(K3a) from Korea, was exactly located in the interval of qC5-11.1 (Kim 2018), but no significant SNP was detected within the candidate genes of $x a 44(t)$, Os11g0690466 and Os11g0690066. Using the 3 K RG 4.8mio filtered SNP Dataset, we found no SNP variation for Os11g0690466 among 340 accessions, while 120 SNPs for Os11g0690066 clustered the accessions into three major haplotypes (Table S4). ANOVA showed no significant difference in LL among three major haplotypes for any Xoo strains used in this study (Fig. S2). Furthermore, we analyzed the expression of $x a 44(t)$ in the resistant and susceptible cultivars, and found no difference between them, suggesting that the SNP variation and expression of $x a 44(t)$ were not responsible for $q C 5$ 11.1 and other genes responsible for $q C 5-11.1$ should be studied.

Chromosome 5, as the second hotspot chromosome, contained one QTL against strain C5 and two QTL against strain V. Both $q C 5-5$ and $q V-5.1$ overlapped with LOC_Os05g01710 (xa5), a recessive gene encoding 


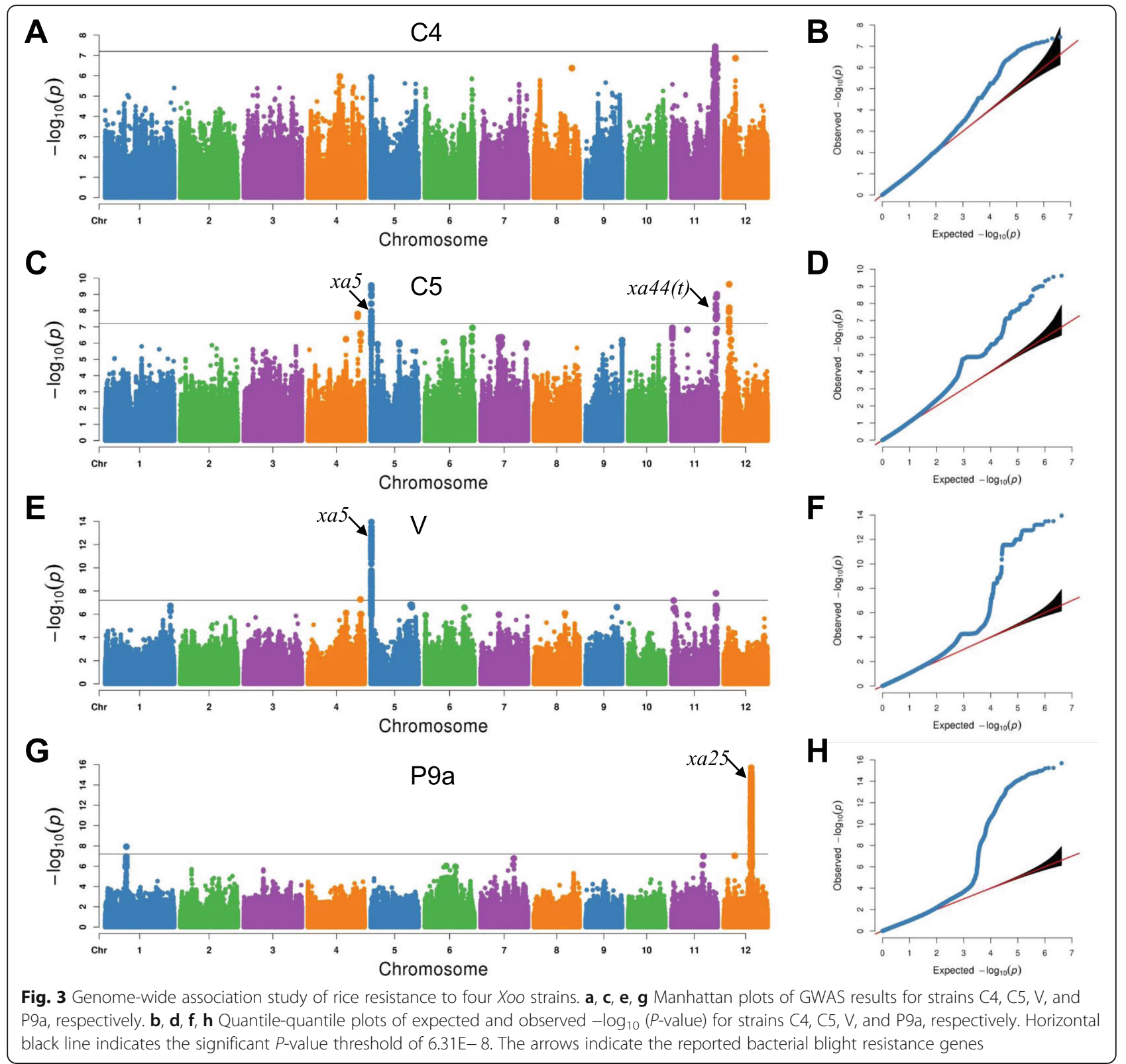

transcription initiation factor IIA subunit 2, responsible for broad-spectrum resistance (Huang et al. 2016; IyerPascuzzi et al. 2008; Mishra et al. 2013). Haplotype analysis of LOC_Os05g01710, based on significant SNPs, showed that accessions carrying Hap2 were more resistant to four strains than those with Hap1 (Fig. S3A, S3B), and the Hap2 allele was authentically xa5. Accessions carrying the Hap2 allele belonged to the cA subgroup, suggesting that cA subgroup could be used as an important resistance source in future breeding programs. Notably, $q V-5.2$ was not reported to be associated with $\mathrm{BB}$ resistance in previous studies (Table 1), and might be a novel BB resistance locus. The lead SNP of $q V-5.2$ (rs5_464,676, $P$-value $=3.55 \mathrm{E}-10)$ was located in the vicinity of transposon gene LOC_Os05g01770 (Table S3), suggesting that this transposon gene might confer resistance to strain $\mathrm{V}$.

Chromosome 12, as the third hotspot chromosome, carried the largest number of QTL, including one QTL for resistance to strain $\mathrm{C} 5$ and three for $\mathrm{P} 9 \mathrm{a}$, but no common QTL was detected for resistance to both strains, indicating that they were controlled by different genes. There were no reported BB resistance genes in the region of $q C 5-12$. The significant SNP rs12_3471439 within $q C 5-12$ contributed to a stop codon gained for a transposon gene (LOC_Os12g07080), potentially the causal gene conferring resistance to C5. Three QTL for resistance to $\mathrm{P} 9 \mathrm{a}$ were all located in the interval of L12 
Table 1 Significant loci for rice bacterial blight resistance obtained from genome-wide association study

\begin{tabular}{|c|c|c|c|c|c|}
\hline $\begin{array}{l}\text { QTL } \\
\text { name }^{a}\end{array}$ & $\begin{array}{l}\text { LD block interval } \\
\text { (bp) }\end{array}$ & $\begin{array}{l}\text { Number of significant } \\
\text { SNP }\end{array}$ & $\begin{array}{l}\text { Lead SNP position } \\
\text { (bp) }\end{array}$ & $\begin{array}{l}\text { Lead SNP } \\
P \text {-value }\end{array}$ & Overlapped with known genes/QTL \\
\hline $9 C 4-11$ & $27,382,744-27,579,384$ & 4 & $27,490,677$ & $3.70 \mathrm{E}-08$ & $\begin{array}{l}\text { L11(Zhang et al. 2017a), } \\
\text { QBbr11-1(Chen et al. 2016) }\end{array}$ \\
\hline$q C 5-4$ & $31,060,503-31,170,315$ & 2 & $31,071,832$ & 1.60E-08 & novel \\
\hline$q C 5-5$ & $283,658-476,382$ & 51 & 348,262 & $2.81 \mathrm{E}-10$ & xa5(lyer-Pascuzzi et al. 2008) \\
\hline$q C 5-11.1$ & $27,985,691-28,013,096$ & 8 & $27,996,768$ & $1.58 \mathrm{E}-09$ & $\begin{array}{l}\text { xa44(t) (Kim 2018), L11 (Zhang et al. 2017a), } \\
\text { QBbr11-2(Chen et al. 2016) }\end{array}$ \\
\hline$q C 5-11.2$ & $28,430,697-28,479,727$ & 7 & $28,479,727$ & $9.75 \mathrm{E}-10$ & $\begin{array}{l}\text { L11(Zhang et al. 2017a), } \\
\text { QBbr11-2(Chen et al. 2016) }\end{array}$ \\
\hline $9 C 5-12$ & $3,460,540-3,549,818$ & 12 & $3,493,693$ & $2.40 \mathrm{E}-10$ & novel \\
\hline$q \vee-5.1$ & $288,855-443,952$ & 272 & 436,664 & $1.14 \mathrm{E}-14$ & xa5(lyer-Pascuzzi et al. 2008) \\
\hline$q V-5.2$ & $444,857-476,382$ & 98 & 464,676 & $3.55 \mathrm{E}-10$ & novel \\
\hline qP9a-12.1 & $17,003,758-17,085,897$ & 65 & $17,016,036$ & $1.58 \mathrm{E}-13$ & L12(Zhang et al. 2017a) \\
\hline qP9a-12.2 & $17,169,665-17,339,744$ & 498 & $17,274,286$ & $2.03 E-16$ & L12(Zhang et al. 2017a), xa25(Liu et al. 2011) \\
\hline$q P 9 a-12.3$ & $17,342,010-17,426,793$ & 610 & $17,402,252$ & 1.03E-14 & L12(Zhang et al. 2017a) \\
\hline
\end{tabular}

${ }^{a} q X-N$ indicates $\mathrm{QTL}$ located on chromosome $\mathrm{N}$ conferring resistance to $\mathrm{X}$

loci, in the range of $16,502,066-17,531,046 \mathrm{bp}$ on chromosome 12, and were also reported to be associated with resistance to P9a (Zhang et al. 2017a). Among them, $q P 9 a-12.2$ harbored a recessive and race-specific gene $x a 25$, associated with resistance to P9a (Liu et al. 2011). Haplotype analysis of xa25, based on significant SNPs, divided the accessions into four major haplotypes (Fig. S4A). A significant difference in LL among different haplotypes was observed only for $\mathrm{P9a}$, confirming the race-specific resistance of $x a 25$ (Fig. S4B).

\section{The Effect of Pyramiding Favorable Alleles on BB Resistance}

To further explore the comprehensive effects of different alleles on the reaction to $\mathrm{BB}$, the number of favorable alleles in each accession were examined. For each QTL, we selected the lead SNP to represent the QTL effect. In general, each accession contained zero to four favorable alleles. Through linear regression analysis, significant correlations were observed between LL and number of favorable allele with $R^{2}=$ $0.88,0.71,0.89$ for $\mathrm{C} 5, \mathrm{~V}$ and P9a, respectively (Fig. S5). For Xoo strains C5 and P9a, the LL of the accessions significantly decreased as the number of favorable allele increased (Fig. S5A, S5C). For V, there was a slight difference between LL and the number of favorable allele (Fig. S5B) and we speculated that this effect might involve the influence of genetic background. In general, the LL of cultivars with multiple favorable alleles was shorter than those with a single allele, but their genetic background should be considered when pyramiding favorable alleles in breeding programs.

\section{LOC_Os11g46250 Positively Regulates Resistance to C5}

Since two candidate genes of $x a 44(t)$ were not responsible for $q C 5-11.1$, we focused on other genes in this region. In the candidate region of $q C 5-11.1$ spanning 27, 985,691-28,013,096 bp, two significant SNPs with $P$ value of 8.80E-09 (rs11_28009272 and rs11_28011447) were exactly located within LOC_Os11g46250, which encodes an uncharacterized protein (Fig. 4a, b). Using these two significant SNPs to perform haplotype analysis, all the accessions were divided into two major haplotypes (Fig. 4b). Intriguingly, the average LL of the accessions carrying Hap2 was significantly shorter than those carrying Hap1 when inoculated with strain C5, indicating that this candidate gene was likely to be associated with BB resistance (Fig. 4c). Transgenic lines carrying a complementary genomic construct of LOC_Os11g46250, amplified from variety Yunlu 102 with the Hap2 allele of LOC_Os11g46250 driven by its native promoter, were obtained. The qRT-PCR analysis revealed that Hap2 was expressed in all transgenic lines but not in the wild-type, while the expression level of Hap1 in the transgenic lines and wild-type had no significant difference (Fig. S6). When inoculated with $\mathrm{C} 5$ to evaluate $\mathrm{BB}$ resistance, the transgenic lines showed significantly shorter lesions compared to the wild-type, with LL decreased by about $50 \%$ at 3 weeks post-inoculation (Fig. 4d). These results demonstrated that $L O C_{-} O s 11 g 46250$ was associated with resistance to Chinese virulent strain $\mathrm{C} 5$ and the Hap2 allele positively regulates resistance against C5.

\section{Discussion}

Accurate genotyping is crucial to the success of any largescale genetic association study (Tam et al. 2019). 

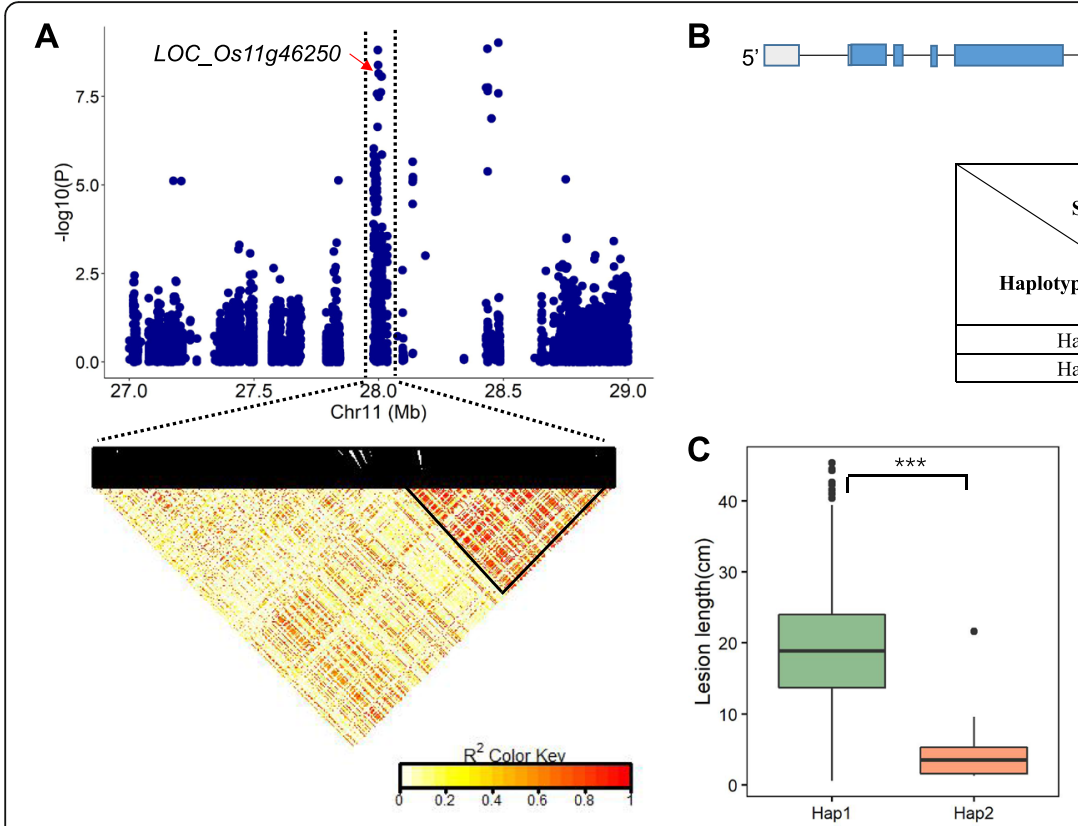

Fig. 4 Analysis of associated region of aC5-11.1 and its candidate gene LOC_Os11g46250. a Manhattan plot (top) and linkage disequilibrium heatmap (bottom) of genomic region surrounding 9C5-11.1. The red arrow indicates the position of significant SNPs located in LOC_Os11946250. b Exon-intron structure and haplotypes of LOC_Os11946250 derived from significant SNPs. Rectangles and lines represent exons and introns, respectively and the coding sequence highlighted in blue. c Lesion length (LL) of accessions with different haplotypes of LOC_Os 11946250 inoculated with strain C5. $\mathbf{d}$ LL of transgenic lines and wild-type inoculated with C5. Box edges represent the 0.25 and 0.75 quantiles with median values indicated by bold lines. ** and ${ }^{* * *}$ refer to significant differences at $P<0.01$ and 0.001 , respectively. WT and CP-1/CP-2/CP-3 refer to wildtype Nipponbare and three independent transgenic lines carrying complementary genomic fragments, respectively

Compared to $44 \mathrm{~K}, 55 \mathrm{~K}$ and $700 \mathrm{~K}$ SNP arrays, SNPs identified from the $3 \mathrm{~K}$ RG 4.8 mio filtered SNP Dataset (derived from the $3 \mathrm{~K} R \mathrm{R} P$ ) in this study were distributed more densely and covered almost all registered genes in the Nipponbare reference genome (Mansueto et al. 2017; McCouch et al. 2016; Meng et al. 2017; Zhao et al. 2011). The sequencing data of the $3 \mathrm{~K}$ RGP have provided a basis for identifying QTL associated with agronomic traits, abiotic resistance and sheath blight resistance in rice (Shi et al. 2017; Zhai et al. 2018; Zhang et al. 2017b; Zhang et al. 2019). In this study, QTL against BB in a diverse rice panel from the $3 \mathrm{~K}$ RGP were dissected through GWAS, and the results obtained provide novel information for rice breeding.

\section{Diverse Reactions to Xoo Strains among Different Accessions}

We evaluated the resistance of 340 rice accessions from the 3 K RGP to BB caused by four Xoo strains. Strain PXO339 is a representative strain of Philippines race 9, and the other three strains were collected in rice growing regions of China. Strain Z173 (C4) is a representative strain of pathotype 4 from the Yangtze River basin (Fang et al. 1990). Strains GD1358 (C5) and V are new virulent strains that arose in Guangdong Province which are currently prevalent in the southern rice-growing regions of China; these two strains are virulent to $R$ genes $X a 4$ and $X a 21$, respectively (Zeng et al. 2002; Zhang 2005). In all, only eight high resistant cultivars with $\mathrm{LL}<5 \mathrm{~cm}$ for all these four strains were identified, including two XI, two GJ, two cA and two Admix cultivars (Table S2). Only one Chinese cultivar, Yunlu 102 (3K_ID CX355), was highly resistant to all four strains. Besides that cultivar, accessions CX134, CX220, CX269 and IRIS_313-11,051 showed a high level of resistance to strains $\mathrm{C} 5$ and $\mathrm{V}$, but only moderate resistance or resistance to $\mathrm{C} 4$ and P9a, except for CX134, which exhibited high susceptibility to P9a (Table S2). These sources of resistant germplasm in different genetic backgrounds can provide valuable material for facilitating breeding for BB resistance.

\section{Comparison with BB QTL and Genes Identified in Previous Studies}

In previous studies, BB resistance QTL and candidate genes were identified from bi-parental populations, MAGIC populations and natural populations (Bandillo et al. 2013; Chen et al. 2016; Descalsota et al. 2018; Dilla-Ermita et al. 2017; Kim and Reinke 2019; Li et al. 2018; Xie et al. 2015; Zhang et al. 2017a), allowing for a comparison between loci in this study and previously reported QTL and genes. Through our use of high-density 
SNP markers, QTL identified in the present research were narrowed down to a small genomic region enabling cross-reference with other reported genes and QTL spanning a larger region.

Of the 11 QTL detected in this study, three QTL on chromosome 11 all exactly overlapped with L11, which was associated with resistance to strains P1 and P6 (Zhang et al. 2017a). QBbr11-1 contained qC4-11, while QBbr11-2 contained $q C 5-11.1$ and $q C 5-11.2$ (Chen et al. 2016). Notably, a recessive BB resistance gene $x a 44(t)$ was also located in the region of $q C 5-11.1$ (Kim 2018). Two QTL on chromosome 5, $q C 5-5$ and $q V-5.1$, were co-located with the broad-spectrum resistance gene xa5 (Iyer-Pascuzzi et al. 2008). Three QTL on chromosome 12 overlapped with L12, which confers resistance to P9a, and $q P 9 a-12.2$ coincided with $x a 25$ and a significant association signal for P9a and P9b on chromosome 12 in previous reports (Liu et al. 2011; Zhang et al. 2017a; Dilla-Ermita et al. 2017). As the loci were identified using different Xoo strains, it was possible that these regions conferred resistance to multiple strains or certain single genes conferred independent resistance and functioned together.

Besides these QTL overlapping with known resistance genes, three QTL $(q C 5-4, q C 5-12, q V-5.2)$ were newly discovered in the present study, located a long distance on the physical map from known BB resistance QTL or genes (Table 1). To our knowledge, this is the first report of QTL associated with prevalent Chinese Xoo strains. In previous research, 172 indica accessions were inoculated with strains $\mathrm{C} 5$ and $\mathrm{V}$, but no resistance loci were detected in that study (Zhang et al. 2017a). The significant SNP rs4_31,060,503 within $q C 5-4$ was located in the promoter of OsHyPRP16 (LOC OsO4g52260), which contained 28 cis-regulatory elements (14 WRKY71OS, 6 WBOXATNPR1, 1 GT1GMSCAM4, 1 WBBOXPCWRKY1, 6 BIHD1OS) that are involved in pathogen, elicitors and disease resistance response (Kapoor et al. 2019). So it might be important to establish whether OsHyPRP16 is responsible for resistance to C5. Also, one significant SNP rs12 3471439 , located within $q C 5-12$ caused a stop codon in the transposon gene LOC_Os12g07080, which might account for the resistance to C5. In the $q V-5.2$ interval, four significant SNPs of LOC_Os05g01760, encoding putative lysine ketoglutarate reductase trans-splicing related 1 , formed two major haplotypes (Table S3; Fig. S7A). The lesions of accessions with Hap2 were significantly shorter than those with Hap1 for strain $\mathrm{V}$ and the other three strains, suggesting that the causal gene underlying the QTL might confer broad-spectrum resistance (Fig. S7B). Thus, these novel QTL and known QTL/genes provide new insights for breeding high-resistant rice cultivars and elucidating the interaction mechanism between Xoo and rice.
Large numbers of transposable elements exist in rice genomes (Carpentier et al. 2019; Liu et al. 2020). Currently, significant progress has been made in understanding the molecular mechanisms of transposonmediated development and defense in plants. For example, some transposon-derived DNA binding proteins, transcription factors and transposases identified in animals, fungi and plants function as developmental regulators in diverse pathways (Bundock and Hooykaas 2005; Feschotte 2008; Robertson 2002). Transposonderived small RNA TE-siR815 were involved in BB resistance (Zhang et al. 2016). Strikingly, we found 376 significant SNPs associated with BB resistance located in or in the vicinity of five transposons and 17 retrotransposons (Table S3). Several transposons and retrotransposon were also anchored by significant SNPs associated with $\mathrm{BB}$ and sheath blight resistance in previous studies (Zhang et al. 2017a; Zhang et al. 2019). However, less is known about the effect of SNPs in transposon on its function. It is necessary to further exploit the mechanism of transposon involved in regulating $\mathrm{BB}$ resistance in the future.

\section{Potential Application of QTL in Rice Breeding}

It is known that chromosome 11 is an important and complex region of the rice genome with respect to $\mathrm{BB}$ resistance, containing mapped or finely-mapped $\mathrm{BB} R$ genes Xa22(t), Xa30(t), Xa32(t), Xa35(t), Xa36(t), Xa39, $X a 40, x a 41(t), X a 43(t)$ and $x a 44(t)$, and cloned genes Xa3/Xa26, Xa4, Xa10, Xa21, Xa23 (https://shigen.nig.ac. $\mathrm{jp} /$ rice/oryzabase/). Because of the wide deployment of single $R$ genes and Xoo-rice coevolution, elite $R$ genes $X a 4$ and $X a 21$ have been overcome by the newlyemerged Xoo strains $\mathrm{C} 5$ and $\mathrm{V}$ in China (Zeng et al. 2002; Zhang 2005). In this study, we identified a novel gene LOC_Os11g46250 within qC5-11.1 that was responsible for positively regulating $\mathrm{C} 5$ resistance (Fig. 4), providing a new gene for rice breeding and enriching our knowledge of $\mathrm{BB} R$ genes on chromosome 11.

Furthermore, chromosome 5 also contains resistance loci for strains $\mathrm{C} 5$ and V. Notably, $q C 5-5$ and $q V-5.1$ partially overlapped, and a broad-spectrum resistance gene $x a 5$ was found to be located exactly in that region (Iyer and McCouch 2004). Based on haplotype analysis and LL, we found accessions carrying Hap2 (xa5) showed greater resistance to strains $\mathrm{C} 4, \mathrm{C} 5, \mathrm{~V}$ and $\mathrm{P} 9 \mathrm{a}$ than those carrying Hap1 (Fig. S3). Also, cultivar IRBB5 carrying $x a 5$ exhibited significantly shorter LL for strains P1, PXO341 (P10), OS198 (C6) and IV than IR24, the recurrent parent of IRBB5 (data unpublished), indicating that $x a 5$ conferred pleiotropic resistance to Xoo strains. As most accessions contain the susceptible allele of $x a 5$, it is likely to improve $\mathrm{BB}$ resistance by editing this gene using the CRISPR/Cas9 technique (Ma and Liu 2016). 
However, a few Xoo strains containing pthXo1, such as PXO99A and PXO71, were compatible with rice plants with $x a 5$ (Huang et al. 2016), suggesting that $x a 5$ should be combined with other genes/QTL to prevent more virulent strains spreading. To this end, $x a 5$ has already been combined with $\mathrm{Xa4}, \mathrm{Xa}, \mathrm{xa} 13$ and $\mathrm{Xa21}$ in other breeding programs (Pradhan et al. 2015; Hsu et al. 2020). Therefore, pyramiding $x a 5$ and other QTL can be an effective and eco-friendly approach for improving BB resistance.

\section{Conclusion}

In the present study, GWAS for bacterial blight resistance was performed with a diverse panel of 340 rice accessions using the $3 \mathrm{~K}$ RG 4.8 mio filtered SNP Dataset and their phenotypes after inoculating with three Chinese Xoo strains and one Philippines strain. Eight known and three novel resistance loci were identified and several candidate genes were predicted through gene annotation and haplotype analysis. Moreover, an uncharacterized gene LOC_Os11g46250 underlying $q C 5-11.1$ was validated as associated with resistance to C5 and the allele of Hap2 positively regulated resistance against C5. Building on our useful new SNP information, QTL pyramiding using marker-assisted selection would be an effective approach for improving BB resistance in rice.

\section{Supplementary Information}

The online version contains supplementary material available at https://doi. org/10.1186/s12284-021-00462-3.

Additional file 1: Table S1. Primers used in this study

Additional file 2: Table S2. Information about the diverse rice panel of 340 accessions used in this study.

Additional file 3: Table S3. Annotation of significant SNPs for bacterial blight resistance in a diverse panel of 340 accessions

Additional file 4: Table S4. Haplotypes of one candidate gene of xa44(t), Os11g0690066

Additional file 5: Fig. S1. Distribution of bacterial blight lesion length among 340 accessions. Box edges represent the 0.25 and 0.75 quantiles with median values indicated by bold lines. Fig. S2. Lesion length of accessions carrying different haplotypes of one candidate gene of $x a 44(t)$, Os11g0690066. Characters above boxplots indicate significant differences according to Duncan's multiple comparison tests $(P<0.05)$. Fig. S3.

Haplotype analysis of xa5. (A) Exon-intron structure and haplotypes based on significant SNPs. Rectangles and lines represent exons and introns, respectively and the coding sequence highlighted in blue. (B) Lesion length of accessions with different haplotypes. Box edges represent the 0.25 and 0.75 quantiles with median values indicated by bold lines. Characters above boxplots indicate significant differences according to Duncan's multiple comparison tests $(P<0.05)$. Fig. S4. Haplotype analysis of xa25. (A) Exon-intron structure and haplotypes based on significant SNPs. Rectangles and lines represent exons and introns, respectively and the coding sequence highlighted in blue. (B) Lesion length of accessions with different haplotypes. Box edges represent the 0.25 and 0.75 quantiles with median values indicated by bold lines. Characters above boxplots indicate significant differences according to Duncan's multiple comparison tests $(P<0.05)$. Fig. S5. Linear regression analysis of the number of favorable alleles and lesion length of $X_{00}$ strains (A) C5, (B) $\vee$ and (C) P9a. Fig. S6. Relative expression level of Hap1 (A) and Hap2 (B) of LOC_Os11g46250 in transgenic lines and wild-type. $U B Q$ denotes the rice ubiquitin gene (LOC_OsO3g13170) as the internal control; ** refers to significant differences at $P<0.01 ; W T$ and $C P-1 / C P-2 / C P-3$ refer to wild-type Nipponbare and three independent transgenic lines carrying complementary genomic fragments, respectively. Fig. S7. Haplotype analysis of

LOC_Os05g01760 underlying qV-5.2. (A) Exon-intron structure and haplotypes based on significant SNPS. Rectangles and lines represent exons and introns, respectively and the coding sequence highlighted in blue. (B) Lesion length of accessions with different haplotypes. Box edges represent the 0.25 and 0.75 quantiles with median values indicated by bold lines. Characters above boxplots indicate significant differences according to Duncan's multiple comparison tests $(P<0.05)$.

\section{Abbreviations}

BB: Bacterial blight; Xoo: Xanthomonas oryzae pv. oryzae; GWAS: Genomewide association study; 3 K RGP: 3000 Rice Genomes Project; LL: Lesion length; MAGIC: Multi-parent advanced generation inter-cross

\section{Acknowledgments}

We thank Prof. Lie-Xian Zeng, Guangdong Academy of Agricultural Sciences, for providing us with Xoo strain V. We thank Huw Tyson, PhD, from Liwen Bianji, Edanz Editing China (www.liwenbianji.cn/ac), for editing the English text of a draft of this manuscript.

\section{Authors' Contributions}

Conceived and designed the experiments: $Y Z$; performed the experiments: $J L, D Z, X S, Y S$; analyzed the data: $J L, C W$; wrote the paper: $J$, YZ. The authors read and approved the final manuscript.

\section{Funding}

This research was supported by grants from the National Natural Science Foundation of China (grant nos. 31661143009 and 31571632), the National Key Research and Development Program of China (project no.

2016YFD0100101), the Bill \& Melinda Gates Foundation (OPP1130530), and the CAAS Innovative Team Award.

\section{Availability of Data and Materials}

The dataset supporting the conclusions of this article is provided within the article and its additional files.

Ethics Approval and Consent to Participate

Not applicable.

\section{Consent for Publication}

Not applicable.

\section{Competing Interests}

The authors declare that they have no competing interests.

\section{Author details}

${ }^{1}$ National Key Facility for Crop Gene Resources and Genetic Improvement, Institute of Crop Sciences, Chinese Academy of Agricultural Sciences, Beijing 100081, China. ${ }^{2}$ College of Agronomy and Biotechnology, China Agricultural University, Beijing 100193, China. ${ }^{3}$ College of Agronomy, Anhui Agricultural University, Hefei 230036, China.

Received: 1 May 2020 Accepted: 12 February 2021

Published online: 27 February 2021

\section{References}

Alexander DH, Novembre J, Lange K (2009) Fast model-based estimation of ancestry in unrelated individuals. Genome Res 19(9):1655-1664

Balding DJ, Nichols RA (1995) A method for quantifying differentiation between populations at multi-allelic loci and its implications for investigating identity and paternity. Genetica 96(1):3-12

Bandillo N, Raghavan C, Muyco PA, Sevilla MA, Lobina IT, Dilla-Ermita CJ, Tung CW, McCouch S, Thomson M, Mauleon R, Singh RK, Gregorio G, Redoña E, Leung H (2013) Multi-parent advanced generation inter-cross (MAGIC) 
populations in rice: progress and potential for genetics research and breeding. Rice (N Y) 6(1):11

Bossa-Castro AM, Tekete C, Raghavan C, Delorean EE, Dereeper A, Dagno K, Koita O, Mosquera $G$, Leung $H$, Verdier V, Leach JE (2018) Allelic variation for broad-spectrum resistance and susceptibility to bacterial pathogens identified in a rice MAGIC population. Plant Biotechnol J 16(9):1559-1568

Bundock P, Hooykaas P (2005) An Arabidopsis hAT-like transposase is essential for plant development. Nature 436:282-284

Carpentier MC, Manfroi E, Wei FJ, Wu HP, Lasserre E, Llauro C, Debladis E, Akakpo R, Hsing Yl, Panaud O (2019) Retrotranspositional landscape of Asian rice revealed by 3000 genomes. Nat Commun 10(1):24

Chen TX, Zhu YJ, Mi XF, Chen K, Meng LJ, Zuo SM, Xu JL (2016) Mapping of QTLs for bacterial blight resistance and screening of resistance materials using MAGIC populations of rice. Zuo Wu Xue Bao 42(10):1437-1447

Chukwu SC, Rafii MY, Ramlee SI, Ismail SI, Hasan MM, Oladosu YA, Magaji UG, Akos I, Olalekan KK (2019) Bacterial leaf blight resistance in rice: a review of conventional breeding to molecular approach. Mol Biol Rep 46(1):1519-1532

Descalsota GIL, Swamy BPM, Zaw H, Inabangan-Asilo MA, Amparado A, Mauleon R, Chadha-Mohanty P, Arocena EC, Raghavan C, Leung H, Hernandez JE, Lalusin AB, Mendioro MS, Diaz M, Reinke R (2018) Genome-wide association mapping in a rice MAGIC plus population detects QTLs and genes useful for biofortification. Front Plant Sci 9:1347

Dilla-Ermita CJ, Tandayu E, Juanillas VM, Detras J, Lozada DN, Dwiyanti MS, Vera Cruz C, Mbanjo EGN, Ardales E, Diaz MG, Mendioro M, Thomson MJ, Kretzschmar T (2017) Genome-wide association analysis tracks bacterial leaf blight resistance loci in rice diverse germplasm. Rice (N Y) 10(1):8

Fang ZD, Xu ZG, Guo CJ, Yin SZ, Wu SZ, Xu XM, Zhang Q (1990) Studies on pathotypes of Xanthomonas campestris pv. oryzae in China. Zhi Wu Bing Li Xue Bao 20(2):81-88

Feng ZM, Kang HX, Li MY, Zou LH, Wang XQ, Zhao JH, Wei L, Zhou NN, Li QQ, Lan Y, Zhang YF, Chen ZX, Liu WD, Pan XB, Wang GL, Zuo SM (2019) Identification of new rice cultivars and resistance loci against rice blackstreaked dwarf virus disease through genome-wide association study. Rice ( $N$ Y) 12(1):49

Feschotte C (2008) Transposable elements and the evolution of regulatory networks. Nature Rev Genet 9(5):397-405

Fuentes RR, Chebotarov D, Duitama J, Smith S, De la Hoz JF, Mohiyuddin M, Wing RA, McNally KL, Tatarinova T, Grigoriev A, Mauleon R, Alexandrov N (2019) Structural variants in 3000 rice genomes. Genome Res 29(5):870-880

Galinsky KJ, Bhatia G, Loh PR, Georgiev S, Mukherjee S, Patterson NJ, Price AL (2016) Fast principal-component analysis reveals convergent evolution of ADH1B in Europe and East Asia. Am J Hum Genet 98(3):456-472

Guo HF, Zeng YW, Li JL, Ma XQ, Zhang ZY, Lou QJ, Li J, Gu YS, Zhang HL, Li JJ, Li ZC (2020) Differentiation, evolution and utilization of natural alleles for cold adaptability at the reproductive stage in rice. Plant Biotechnol J 18(12):24912503

Hsu YC, Chiu CH, Yap R, Tseng YC, Wu YP (2020) Pyramiding bacterial blight resistance genes in Tainung 82 for broad-spectrum resistance using markerassisted selection. Int J Mol Sci 21(4):1281

Hu KM, Cao JB, Zhang J, Xia F, Ke YG, Zhang HT, Xie WY, Liu HB, Cui Y, Cao YL, Sun XL, Xiao JH, Li XH, Zhang QL, Wang SP (2017) Improvement of multiple agronomic traits by a disease resistance gene via cell wall reinforcement. Nat Plants 3:17009

Huang S, Antony G, Li T, Liu B, Obasa K, Yang B, White FF (2016) The broadly effective recessive resistance gene $x a 5$ of rice is a virulence effectordependent quantitative trait for bacterial blight. Plant J 86(2):186-194

Huang XH, Yang SH, Gong JY, Zhao Y, Feng Q, Gong H, Li WJ, Zhan QL, Cheng BY, Xia JH, Chen N, Hao ZN, Liu KY, Zhu CR, Huang T, Zhao Q, Zhang L, Fan DL, Zhou CC, Lu YQ, Weng QJ, Wang ZX, Li JY, Han B (2015) Genomic analysis of hybrid rice varieties reveals numerous superior alleles that contribute to heterosis. Nat Commun 6:6258

lyer AS, McCouch SR (2004) The rice bacterial blight resistance gene xa5 encodes a novel form of disease resistance. Mol Plant-Microbe Interact 17(12):1348-1354

lyer-Pascuzzi AS, Jiang H, Huang L, McCouch SR (2008) Genetic and functional characterization of the rice bacterial blight disease resistance gene $x a 5$. Phytopathology 98:289-295

Kang HM, Sul JH, Service SK, Zaitlen NA, Kong SY, Freimer NB, Sabatti C, Eskin E (2010) Variance component model to account for sample structure in genome-wide association studies. Nat Genet 42(4):348-354

Kang HX, Wang Y, Peng SS, Zhang YL, Xiao YH, Wang D, Qu SH, Li ZQ, Yan SY, Wang ZL, Liu WD, Ning YS, Korniliev P, Leung H, Mezey J, McCouch SR,
Wang GL (2016) Dissection of the genetic architecture of rice resistance to the blast fungus Magnaporthe oryzae. Mol Plant Pathol 17(6):959-972

Kapoor R, Kumar G, Arya P, Jaswal R, Jain P, Singh K, Sharma TR (2019) Genomewide analysis and expression profiling of rice hybrid proline-rich proteins in response to biotic and abiotic stresses, and hormone treatment. Plants (Basel) 8(9):343

Kauffman HE, Reddy APK, Hsieh SPY, Merca SD (1973) An improved technique for evaluating resistance of rice varieties to Xanthomonas oryzae. Plant Dis Rep 57(6):537-541

Kim SM (2018) Identification of novel recessive gene $x a 44(t)$ conferring resistance to bacterial blight races in rice by QTL linkage analysis using an SNP chip. Theor Appl Genet 131(12):2733-2743

Kim SM, Reinke RF (2019) A novel resistance gene for bacterial blight in rice, Xa43(t) identified by GWAS, confirmed by QTL mapping using a bi-parental population. PLoS One 14(2):e0211775

Letunic I, Bork P (2006) Interactive tree of life (iTOL): an online tool for phylogenetic tree display and annotation. Bioinformatics 23(1):127-128

Li CG, Su P, Wang D, Peng SS, Chen Y, Chen JB, Tan XQ, Zhang DY, Wang GL, Liu $Y$ (2018) Dissection of the genetic architecture of rice resistance to Xanthomonas oryzae pv. oryzae using a genomewide association study. J Phytopathol 166:470-476

Li CG, Wang D, Peng SS, Chen Y, Su P, Chen JB, Zheng LM, Tan XQ, Liu JL, Xiao YH, Kang HX, Zhang DY, Wang GL, Liu Y (2019a) Genome-wide association mapping of resistance against rice blast strains in South China and identification of a new Pik allele. Rice (N Y) 12(1):47

Li CY, Li W, Zhou ZH, Chen H, Xie CH, Lin YJ (2020) A new rice breeding method: CRISPR/Cas9 system editing of the Xa13 promoter to cultivate transgene-free bacterial blight-resistant rice. Plant Biotechnol J 18(2):313-315

Li FJ, Wen WE, Liu JD, Zhang Y, Cao SH, He ZH, Rasheed A, Jin H, Zhang C, Yan J, Zhang PZ, Wan YX, Xia XC (2019b) Genetic architecture of grain yield in bread wheat based on genome-wide association studies. BMC Plant Biol 19(1):168

Li M, Yeung J, Cherny S, Sham P (2012) Evaluating the effective numbers of independent tests and significant p-value thresholds in commercial genotyping arrays and public imputation reference datasets. Hum Genet 131(5):747-756

Liu JD, He ZH, Rasheed A, Wen WE, Yan J, Zhang PZ, Wan YX, Zhang Y, Xie CJ, Xia XC (2017) Genome-wide association mapping of black point reaction in common wheat (Triticum aestivum L.). BMC Plant Biol 17(1):220

Liu QS, Yuan M, Zhou Y, Li XH, Xiao JH, Wang SP (2011) A paralog of the MtN3/ saliva family recessively confers race-specific resistance to Xanthomonas oryzae in rice. Plant Cell Environ 34(11):1958-1969

Liu Z, Wang TZ, Wang L, Zhao H, Yue EK, Yan Y, Irshad F, Zhou L, Duan MH, Xu JH (2020) RTRIP: a comprehensive profile of transposon insertion polymorphisms in rice. Plant Biotechnol J 18(12):2379-2381

Ma XL, Liu YG (2016) CRISPR/Cas9-based multiplex genome editing in monocot and dicot plants. Curr Protoc Mol Biol 115:31.6.1-31.6.21

Mansueto L, Fuentes RR, Borja FN, Detras J, Abriol-Santos JM, Chebotarov D, Sanciangco M, Palis K, Copetti D, Poliakov A, Dubchak I, Solovyev V, Wing RA, Hamilton RS, Mauleon R, McNally KL, Alexandrov N (2017) Rice SNP-seek database update: new SNPs, indels, and queries. Nucleic Acids Res 45(D1): D1075-D1081

McCouch SR, Wright MH, Tung CW, Maron LG, McNally KL, Fitzgerald M, Singh N, DeClerck G, Agosto-Perez F, Korniliev P, Greenberg AJ, Naredo MEB, Mercado SMQ, Harrington SE, Shi Y, Branchini DA, Kuser-Falcão PR, Leung H, Ebana K, Yano M, Eizenga G, McClung A, Mezey J (2016) Open access resources for genome-wide association mapping in rice. Nat Commun 7(1):10532

McDonald BA, Linde C (2002) Pathogen population genetics, evolutionary potential, and durable resistance. Annu Rev Phytopathol 40:349-379

Men X, Shi JX, Liang WQ, Zhang QF, Lian GB, Quan S, Zhu L, Luo ZJ, Chen MJ, Zhang DB (2017) Glycerol-3-phosphate Acyltransferase 3 (OsGPAT3) is required for anther development and male fertility in rice. J Exp Bot 68(3):513-526

Meng $\sqcup$, Wang BX, Zhao XQ, Ponce K, Qian Q, Ye GY (2017) Association mapping of ferrous, zinc, and aluminum tolerance at the seedling stage in Indica rice using MAGIC populations. Front Plant Sci 8:1822

Mew T (1978) Current status and future prospects of research on bacterial blight of rice. Annu Rev Phytopathol 25:359-382

Mishra D, Vishnupriya MR, Anil MG, Konda K, Raj Y, Sonti RV (2013) Pathotype and genetic diversity amongst Indian isolates of Xanthomonas oryzae pv. oryzae. PLoS One 8(11):e81996

Neelam K, Mahajan R, Gupta V, Bhatia D, Gill BK, Komal R, Lore JS, Mangat GS, Singh K (2020) High-resolution genetic mapping of a novel bacterial blight 
resistance gene $x a-45(t)$ identified from Oryza glaberrima and transferred to Oryza sativa. Theor Appl Genet 133(3):689-705

Niño-Liu DO, Ronald PC, Bogdanove AJ (2006) Xanthomonas oryzae pathovars: model pathogens of a model crop. Mol Plant Pathol 7(5):303-324

Nishimura A, Aichi I, Matsuoka M (2006) A protocol for Agrobacterium-mediated transformation in rice. Nat Protoc 1(6):2796-2802

Oerke EC (2006) Crop losses to pests. J Agric Sci 144(1):31-43

Peng H, Wang K, Chen Z, Cao YH, Gao Q, Li Y, Li XX, Lu HW, Du HL, Lu M, Yang X, Liang CZ (2020) MBKbase for rice: an integrated omics knowledgebase for molecular breeding in rice. Nucleic Acids Res 48(D1):D1085-D1092

Pradhan SK, Nayak DK, Mohanty S, Behera L, Barik SR, Pandit E, Lenka S, Anandan A (2015) Pyramiding of three bacterial blight resistance genes for broadspectrum resistance in deepwater rice variety, Jalmagna. Rice (N Y) 8(1):51

Purcell S, Neale B, Todd-Brown K, Thomas L, Ferreira MAR, Bender D, Maller J, Sklar P, de Bakker PIW, Daly MJ, Sham PC (2007) PLINK: a tool set for wholegenome association and population-based linkage analyses. Am J Hum Genet 81(3):559-575

Robertson HM (2002) Evolution of DNA transposons in eukaryotes. In: Craig NL, Craigie R, Gellert M, Lambowitz AM (eds) Mobile DNA II. ASM Press, Washington, pp 1093-1110

Shi YY, Gao LL, Wu ZC, Zhang XJ, Wang MM, Zhang CS, Zhang F, Zhou YL, Li ZK (2017) Genome-wide association study of salt tolerance at the seed germination stage in rice. BMC Plant Biol 17(1):92

Shimada MK, Nishida T (2017) A modification of the PHYLIP program: a solution for the redundant cluster problem, and an implementation of an automatic bootstrapping on trees inferred from original data. Mol Phylogenet Evol 109: 409-414

Shin J-H, Blay S, McNeney B, Graham J (2006) LDheatmap: an R function for graphical display of pairwise linkage disequilibria between single nucleotide polymorphisms. J Stat Softw 16:code snippet 3

Song WY, Pi LY, Wang GL, Gardner J, Holsten T, Ronald PC (1997) Evolution of the rice $X a 21$ disease resistance gene family. Plant Cell 9:1279-1287

Sun LP, Xiang XJ, Yang ZF, Yu P, Wen XX, Wang H, Abbas A, Muhammad Khan R, Zhang YX, Cheng SH, Cao LY (2018) OsGPAT3 plays a critical role in anther wall programmed cell death and pollen development in rice. Int J Mol Sci 19(12):4017

Takeda S, Matsuoka M (2008) Genetic approaches to crop improvement: responding to environmental and population changes. Nat Rev Genet 9(6): 444-457

Tam V, Patel N, Turcotte M, Bossé Y, Paré G, Meyre D (2019) Benefits and limitations of genome-wide association studies. Nat Rev Genet 20(8):467-484

Wang CC, Yu H, Huang J, Wang WS, Faruquee M, Zhang F, Zhao XQ, Fu BY, Chen K, Zhang HL, Tai SS, Wei CC, McNally KL, Alexandrov N, Gao XY, Li JY, Li ZK, Xu JL, Zheng TQ (2020) Towards a deeper haplotype mining of complex traits in rice with RFGB v2.0. Plant Biotechnol J 18(1):14-16

Wang CL, Zhang XP, Fan YL, Gao Y, Zhu QL, Zheng CK, Qin TF, Li YQ, Che JY, Zhang MW, Yang B, Liu YG, Zhao KJ (2015) XA23 is an executor R protein and confers broad-spectrum disease resistance in rice. Mol Plant 8(2):290-302

Wang CS, Tang SC, Zhan QL, Hou QQ, Zhao Y, Zhao Q, Feng Q, Zhou CC, Lyu DF, Cui LL, Li Y, Miao JS, Zhu CR, Lu YQ, Wang YC, Wang ZQ, Zhu JJ, Shangguan YY, Gong JY, Yang SH, Wang WQ, Zhang JF, Xie HA, Huang XH, Han B (2019) Dissecting a heterotic gene through GradedPool-Seq mapping informs a rice-improvement strategy. Nat Commun 10(1):2982

Wang WS, Mauleon R, Hu ZQ, Chebotarov D, Tai SS, Wu ZC, Li M, Zheng TQ, Fuentes RR, Zhang F, Mansueto L, Copetti D, Sanciangco M, Palis KC, Xu JL, Sun C, Fu BY, Zhang HL, Gao YM, Zhao XQ, Shen F, Cui X, Yu H, Li ZC, Chen ML, Detras J, Zhou YL, Zhang XY, Zhao Y, Kudrna D, Wang CC, Li R, Jia B, Lu JY, He XC, Dong ZT, Xu JB, Li YH, Wang M, Shi JX, Li J, Zhang DB, Lee S, Hu WS, Poliakov A, Dubchak I, Ulat VJ, Borja FN, Mendoza JR, Ali J, Li J, Gao Q, Niu YC, Yue Z, Naredo MEB, Talag J, Wang XQ, Li JJ, Fang XD, Yin Y, Glaszmann JC, Zhang JW, Li JY, Hamilton RS, Wing RA, Ruan J, Zhang GY, Wei CC, Alexandrov N, McNally KL, Li ZK, Leung H (2018) Genomic variation in 3,010 diverse accessions of Asian cultivated rice. Nature 557(7703):43-49

Wang XL, Wang HW, Liu SX, Ferjani A, Li JS, Yan JB, Yang XH, Qin F (2016) Genetic variation in ZmVPP1 contributes to drought tolerance in maize seedlings. Nat Genet 48(10):1233-1241

Wickham H (2009) ggplot2: elegant graphics for data analysis. Springer-Verlag, New York. https://doi.org/10.1007/978-0-387-98141-3

Xie WB, Wang GW, Yuan M, Yao W, Lyu K, Zhao H, Yang M, Li PB, Zhang X, Yuan J, Wang QX, Liu F, Dong HX, Zhang LJ, Li XL, Meng XZ, Zhang W, Xiong LZ, He YQ, Wang SP, Yu SB, Xu CG, Luo J, Li XH, Xiao JH, Lian XM, Zhang QF
(2015) Breeding signatures of rice improvement revealed by a genomic variation map from a large germplasm collection. Proc Natl Acad Sci U S A 112(39):E5411-E5419

Yano K, Morinaka Y, Wang FM, Huang P, Takehara S, Hirai T, Ito A, Koketsu E, Kawamura M, Kotake K, Yoshida S, Endo M, Tamiya G, Kitano H, UeguchiTanaka M, Hirano K, Matsuoka M (2019) GWAS with principal component analysis identifies a gene comprehensively controlling rice architecture. Proc Natl Acad Sci U S A 116(42):21262-21267

Yano K, Yamamoto E, Aya K, Takeuchi H, Lo PC, Hu L, Yamasaki M, Yoshida S, Kitano H, Hirano K, Matsuoka M (2016) Genome-wide association study using whole-genome sequencing rapidly identifies new genes influencing agronomic traits in rice. Nat Genet 48(8):927-934

Zeng LX, Huang SH, Wu SZ (2002) Resistance of IRBB21 (Xa21) to five races of bacterial blight in Guangdong. Zhi Wu Bao Hu Xue Bao 29(2):97-100

Zhai LY, Zheng TQ, Wang XY, Wang Y, Chen K, Wang S, Wang Y, Xu JL, Li ZK (2018) QTL mapping and candidate gene analysis of peduncle vascular bundle related traits in rice by genome-wide association study. Rice (N Y) 11(1):13

Zhai LY, Wang F, Yan A, Liang CW, Wang S, Wang Y, Xu JL (2020) Pleiotropic effect of GNP1 underlying grain number per panicle on sink, source and flow in rice. Front Plant Sci 11:93

Zhang F, Wu ZC, Wang MM, Zhang F, Dingkuhn M, Xu JL, Zhou YL, Li ZK (2017a) Genome-wide association analysis identifies resistance loci for bacterial blight in a diverse collection of indica rice germplasm. PLoS One 12(3):e0174598

Zhang F, Zeng D, Zhang CS, Lu JL, Chen TJ, Xie JP, Zhou YL (2019) Genome-wide association analysis of the genetic basis for sheath blight resistance in rice. Rice (N Y) 12(1):93

Zhang F, Zhuo DL, Zhang F, Huang LY, Wang WS, Xu JL, Vera Cruz C, Li ZK, Zhou YL (2015) Xa39, a novel dominant gene conferring broad-spectrum resistance to Xanthomonas oryzae pv. oryzae in rice. Plant Pathol 64(3):568-575

Zhang HT, Tao Z, Hong HM, Chen ZH, Wu CY, Li XH, Xiao JH, Wang SP (2016) Transposon-derived small RNA is responsible for modified function of WRKY45 locus. Nat Plants 2:16016

Zhang J, Chen K, Pang YL, Naveed SA, Zhao XQ, Wang XQ, Wang Y, Dingkuhn M, Pasuquin J, Li ZK, Xu JL (2017b) QTL mapping and candidate gene analysis of ferrous iron and zinc toxicity tolerance at seedling stage in rice by genome-wide association study. BMC Genomics 18(1):828

Zhang Q (2005) Highlights in identification and application of resistance genes to bacterial blight. Zhongguo Shuidao Kexue 19(5):453-459

Zhang Q (2009) Genetics and improvement of bacterial blight resistance of hybrid rice in China. Rice Sci 16(2):83-92

Zhao KY, Tung CW, Eizenga GC, Wright MH, Ali ML, Price AH, Norton GJ, Islam MR, Reynolds A, Mezey J, McClung AM, Bustamante CD, McCouch SR (2011) Genome-wide association mapping reveals a rich genetic architecture of complex traits in Oryza sativa. Nat Commun 2(1):467

Zhao $Y$, Zhang $H L$, Xu JL, Jiang $C H$, Yin ZG, Xiong HY, Xie JY, Wang $X Q$, Zhu XY, Li Y, Zhao WP, Rashid MAR, Li JJ, Wang WS, Fu BY, Ye GY, Guo Y, Hu ZQ, Li ZK, Li ZC (2018) Loci and natural alleles underlying robust roots and adaptive domestication of upland ecotype rice in aerobic conditions. PLoS Genet 14(8):e1007521

Zhou YL, Zhang Q (1999) Preliminary report on the isolation technique of Ustilagonoidea virens (Cooke) Tak. Zhongguo Shuidao Kexue 13(3):186-188

\section{Publisher's Note}

Springer Nature remains neutral with regard to jurisdictional claims in published maps and institutional affiliations. 